\title{
New Topologically Unique Metal-Organic Architectures Driven by a Pyridine-Tricarboxylate Building Block
}

\author{
Jinzhong Gu ${ }^{1, *}$, Yan Cai ${ }^{1}$, Min Wen ${ }^{1}$, Zhijun Ge ${ }^{2}$ and Alexander M. Kirillov ${ }^{3,4, *(1)}$ \\ 1 College of Chemistry and Chemical Engineering, Lanzhou University, Lanzhou 730000, China; \\ caiy2016@lzu.edu.cn (Y.C.); wenm17@lzu.edu.cn (M.W.) \\ 2 The Yixing Medical Center of Jiangsu University, Yixing 214200, China; staff789@yxph.com \\ 3 Centro de Química Estrutural, Instituto Superior Técnico, Universidade de Lisboa, Av. Rovisco Pais, \\ 1049-001 Lisbon, Portugal \\ 4 Peoples' Friendship University of Russia (RUDN University), 6 Miklukho-Maklaya st., \\ Moscow 117198, Russia \\ * Correspondence: gujzh@lzu.edu.cn (J.G.); kirillov@tecnico.ulisboa.pt (A.M.K.); Tel.: +86-931-8915-196 (J.G.)
}

Received: 29 July 2018; Accepted: 23 August 2018; Published: 3 September 2018

\begin{abstract}
Two new three-dimensional (3D) coordination compounds, namely a lead(II) coordination polymer (CP) $\left\{\left[\mathrm{Pb}_{3}\left(\mu_{5} \text {-cpta }\right)\left(\mu_{6} \text {-cpta) (phen }\right)_{2}\right] \cdot 2 \mathrm{H}_{2} \mathrm{O}\right\}_{\mathrm{n}}$ (1) and a zinc(II) metal-organic framework (MOF) $\left\{\left[\mathrm{Zn}_{2}\left(\mu_{4} \text {-cpta }\right)(\mu-\mathrm{OH})\left(\mu-4,4^{\prime} \text {-bipy) }\right] \cdot 6 \mathrm{H}_{2} \mathrm{O}\right\}_{n}\right.$ (2), were hydrothermally assembled from 2-(5-carboxypyridin-2-yl)terephthalic acid $\left(\mathrm{H}_{3} \mathrm{cpta}\right)$ as an unexplored principal building block and aromatic $\mathrm{N}, \mathrm{N}$-donors as crystallization mediators. Both products were isolated as air-stable microcrystalline solids and were fully characterized by IR spectroscopy, elemental and thermogravimetric analysis, and powder and single-crystal X-ray diffraction. Structural and topological features of CP 1 and MOF 2 were analyzed in detail, allowing to identify a topologically unique 4,5,5,6-connected net in $\mathbf{1}$ or a very rare 4,4-connected net with the isx topology in 2 . Thermal stability and solid-state luminescent behavior of $\mathbf{1}$ and $\mathbf{2}$ were also investigated. Apart from revealing a notable topological novelty, both compounds also represent the first structurally characterized $\mathrm{Pb}(\mathrm{II}) \mathrm{and}$ $\mathrm{Zn}$ (II) derivatives assembled from $\mathrm{H}_{3}$ cpta, thus opening up the application of this unexplored pyridine-tricarboxylate block in the design of new metal-organic architectures.
\end{abstract}

Keywords: metal-organic frameworks; hydrothermal synthesis; crystal structure; coordination chemistry; coordination polymers

\section{Introduction}

The research on metal-organic frameworks (MOFs) has become a very hot topic in materials science, especially given their almost infinite structural diversity [1-3] and notable functional properties, with significance in the areas of luminescent materials [4-6], molecular magnetism [7-10], gas storage [11-13], sensing and separation [14-16], and catalysis [17-20]. A high diversity of factors can affect the metal-organic architectures and functional properties of MOFs, such as, for example, the nature and coordination preferences of metal nodes, types of organic spacers, and linkers, and various reaction conditions [21-26].

More specifically, for the design of MOFs, it is interesting to explore different aromatic carboxylic acids as flexible and stable building blocks with modifiable backbones and coordination preferences, along with the metal nodes that can exhibit unusual coordination preferences [27-30]. Although multicarboxylate building blocks are among the most common ones used in the synthesis of MOFs, different aromatic $N, N$-donors also play an important role and frequently act as ancillary ligands 
to adjust the coordination modes of carboxylate spacers, to provide reinforcement of metal-organic networks via additional supramolecular interactions, or to facilitate crystallization [16,26,31-34].

Following our interest in the exploration of novel and poorly investigated multicarboxylic acids for the design of metal-organic architectures [21,22,24-27], in the present study we selected 2-(5-carboxypyridin-2-yl)terephthalic acid $\left(\mathrm{H}_{3} \mathrm{cpta}\right)$ as a main pyridine-tricarboxylate building block. Its choice is governed by the following reasons: (A) $\mathrm{H}_{3}$ cpta can potentially act as an excellent bridging ligand to construct MOFs, given the presence in its structure of three $\mathrm{COOH}$ groups along with an $N$-pyridyl functionality; (B) $\mathrm{H}_{3}$ cpta features a flexibility wherein pyridyl and phenyl rings can rotate around the $\mathrm{C}-\mathrm{C}$ single bond; and (C) $\mathrm{H}_{3}$ cpta is thermally stable and remains largely unexplored for the construction of MOFs, as attested by a search of the Cambridge Structural Database.

Hence, we report herein the hydrothermal synthesis, full characterization, thermal behavior, structural features, topological analysis, and luminescent properties of two novel lead(II) and zinc(II) 3D coordination compounds with very complex and topologically unusual metal-organic architectures. The obtained compounds represent the first structurally characterized $\mathrm{Pb}$ (II) and $\mathrm{Zn}$ (II) derivatives assembled from 2-(5-carboxypyridin-2-yl)terephthalic acid.

\section{Experimental}

\subsection{Materials and Physical Measurements}

All chemicals were of analytical reagent grade and used as received. $\mathrm{H}_{3} \mathrm{cpta}$ was obtained from Jinan Henghua Sci. and Tec. Co., Ltd., Jinan, China. IR spectra were recorded on a Bruker EQUINOX 55 spectrometer (Bruker Corporation, Billerica, MA, USA) using KBr pellets. Elemental $(\mathrm{C}, \mathrm{H}, \mathrm{N})$ analyses were run on an Elementar Vario EL elemental analyzer (Elementar, Langenselbold, Germany). Thermogravimetric analyses (TGA) were performed under $\mathrm{N}_{2}$ atmosphere using a LINSEIS STA PT1600 thermal analyzer (Linseis Messgeräte $\mathrm{GmbH}$, Selb, Germary) with a heating rate of $10{ }^{\circ} \mathrm{C} / \mathrm{min}$. Powder X-ray diffraction patterns (PXRD) were measured on microcrystalline samples using a Rigaku-Dmax 2400 diffractometer (Rigaku Corporation, Tokyo, Japan) with a Cu-K $\alpha$ radiation $(\lambda=1.54060 \AA$ A $)$. Solid-state excitation and emission spectra were measured on an Edinburgh FLS920 fluorescence spectrometer (Edinburgh Instruments, Edinburgh, England) at room temperature.

\subsection{Synthesis of $\left\{\left[\mathrm{Pb}_{3}\left(\mu_{5}-\mathrm{cpta}\right)\left(\mu_{6}-\mathrm{cpta}\right)(\text { phen })_{2}\right] \cdot 2 \mathrm{H}_{2} \mathrm{O}\right\}_{n}(\mathbf{1})$}

A mixture of $\mathrm{PbCl}_{2}$ (113.7 mg, $\left.0.3 \mathrm{mmol}\right), \mathrm{H}_{3}$ cpta $(57.2 \mathrm{mg}, 0.2 \mathrm{mmol})$, phen (59.4 mg, $\left.0.3 \mathrm{mmol}\right)$, $\mathrm{NaOH}(24.0 \mathrm{mg}, 0.6 \mathrm{mmol})$, and $\mathrm{H}_{2} \mathrm{O}(10 \mathrm{~mL})$ was stirred at room temperature for $15 \mathrm{~min}$. Then, it was sealed in a $25 \mathrm{~mL}$ Teflon-lined stainless steel vessel and heated at $160^{\circ} \mathrm{C}$ for three days, followed by cooling to room temperature at a rate of $10{ }^{\circ} \mathrm{C} / \mathrm{h}$. Colorless block-shaped crystals were isolated manually, washed with distilled $\mathrm{H}_{2} \mathrm{O}$, and dried in air to give compound 1. Yield: $60 \%$ (based on $\mathrm{H}_{3}$ cpta). Calcd for $\mathrm{C}_{52} \mathrm{H}_{32} \mathrm{~Pb}_{3} \mathrm{~N}_{6} \mathrm{O}_{14}$ : C 39.37, $\mathrm{H}$ 2.03, N 5.30\%. Found: $\mathrm{C} 39.06, \mathrm{H} 2.01, \mathrm{~N} 5.33 \%$. IR $\left(\mathrm{KBr}, \mathrm{cm}^{-1}\right)$ : 3393 w, 3044 w, 1592 s, 1568 s, 1546 s, 1522 s, 1370 s, 1265 w, 1137 w, 1097 w, 1044 w, $1021 \mathrm{w}, 892 \mathrm{w}, 846 \mathrm{~m}, 805 \mathrm{w}, 764 \mathrm{~m}, 723 \mathrm{~m}, 630 \mathrm{w}, 554 \mathrm{w}$.

\subsection{Synthesis of $\left\{\left[\mathrm{Zn}_{2}\left(\mu_{4}-\mathrm{cpta}\right)(\mu-\mathrm{OH})\left(4,4^{\prime}-\right.\right.\right.$ bipy $\left.)\right] \cdot 6 \mathrm{H}_{2} \mathrm{O}_{n}$ (2)}

A mixture of $\mathrm{ZnCl}_{2}$ ( $\left.81.8 \mathrm{mg}, 0.3 \mathrm{mmol}\right), \mathrm{H}_{3}$ cpta $(57.2 \mathrm{mg}, 0.2 \mathrm{mmol}), 4,4^{\prime}$-bipy ( $\left.46.8 \mathrm{mg}, 0.3 \mathrm{mmol}\right)$, $\mathrm{NaOH}(24.0 \mathrm{mg}, 0.6 \mathrm{mmol})$, and $\mathrm{H}_{2} \mathrm{O}(10 \mathrm{~mL})$ was stirred at room temperature for $15 \mathrm{~min}$. Then, it was sealed in a $25 \mathrm{~mL}$ Teflon-lined stainless steel vessel and heated at $160{ }^{\circ} \mathrm{C}$ for three days, followed by cooling to room temperature at a rate of $10^{\circ} \mathrm{C} / \mathrm{h}$. Colorless block-shaped crystals were isolated manually, washed with distilled $\mathrm{H}_{2} \mathrm{O}$, and dried in air to give compound 2. Yield: $45 \%$ (based on $\mathrm{H}_{3}$ cpta). Calcd for $\mathrm{C}_{24} \mathrm{H}_{27} \mathrm{Zn}_{2} \mathrm{~N}_{3} \mathrm{O}_{13}$ : C 41.40, H 3.91, N 6.03\%. Found: C 41.63, H 3.92, N 5.99\%. IR $\left(\mathrm{KBr}, \mathrm{cm}^{-1}\right): 3614 \mathrm{w}, 3288 \mathrm{w}, 1603 \mathrm{~s}, 1493 \mathrm{w}, 1417 \mathrm{w}, 1376 \mathrm{~s}, 1277 \mathrm{w}, 1213 \mathrm{w}, 1160 \mathrm{w}, 1125 \mathrm{w}, 1068 \mathrm{w}$, $1044 \mathrm{w}, 1015 \mathrm{w}, 864 \mathrm{w}, 840 \mathrm{w}, 817 \mathrm{w}, 776 \mathrm{w}, 717 \mathrm{w}, 642 \mathrm{w}, 571 \mathrm{w}$. 


\subsection{X-ray Crystallography}

Single-crystal X-ray data for $\mathbf{1}$ and $\mathbf{2}$ were collected on a Bruker APEX-II CCD diffractometer (Bruker Corporation, Billerica, MA, USA), using a graphite-monochromated Mo K $\alpha$ radiation $(\lambda=$ $0.71073 \AA$ ). Semiempirical absorption corrections were applied using the SADABS program. Crystal structures were determined using direct methods and refined by full-matrix least-squares on $F^{2}$ with the SHELXS-97 and SHELXL-97 programs [35,36]. All the non-H atoms were refined anisotropically by full-matrix least-squares methods on $F^{2}$. All the $\mathrm{H}$ atoms (except those of $\mathrm{H}_{2} \mathrm{O}$ and $\mathrm{OH}$ moieties) were placed in calculated positions with fixed isotropic thermal parameters, and included in structure factor calculations at the final stage of full-matrix least-squares refinement. Hydrogen atoms of $\mathrm{H}_{2} \mathrm{O}$ and $\mathrm{OH}$ moieties were located by difference maps and constrained to ride on their parent oxygen atoms. Some lattice solvent molecules in $\mathbf{2}$ are highly disordered and were removed using the SQUEEZE routine in PLATON (University of Glasgow, Glasgow, UK) [37]. The number of solvent $\mathrm{H}_{2} \mathrm{O}$ molecules was obtained on the basis of elemental and thermogravimetric analyses. Crystal data for $\mathbf{1}$ and $\mathbf{2}$ are given in Table 1. Selected bond lengths and hydrogen bonding details are given in Tables S1 and S2, respectively (Supplementary Material). Topological analysis of metal-organic networks was performed following the concept of the simplified underlying net [38]. Such nets were obtained by eliminating the terminal ligands [38] and contracting the bridging ligands to centroids and maintaining their connectivity [39]. CCDC-1840702 and 1840703 for 1 and 2 contain the supplementary crystallographic data.

Table 1. Crystal data for compounds 1 and 2.

\begin{tabular}{|c|c|c|}
\hline Compound & 1 & 2 \\
\hline Chemical formula & $\mathrm{C}_{52} \mathrm{H}_{32} \mathrm{~Pb}_{3} \mathrm{~N}_{6} \mathrm{O}_{14}$ & $\mathrm{C}_{24} \mathrm{H}_{27} \mathrm{Zn}_{2} \mathrm{~N}_{3} \mathrm{O}_{13}$ \\
\hline Molecular weight & 1586.40 & 696.18 \\
\hline Crystal system & Monoclinic & Monoclinic \\
\hline Space group & $P \mathrm{n}$ & $\mathrm{C} 2 / \mathrm{c}$ \\
\hline$a / \AA$ & $16.1620(4)$ & $24.2264(8)$ \\
\hline$b / \AA ̊$ & $8.61606(17)$ & $19.3903(9)$ \\
\hline$c / \AA$ & $18.3591(4)$ & $4.0603(6)$ \\
\hline$\alpha /\left(^{\circ}\right)$ & 90 & 90 \\
\hline$\beta /\left(^{\circ}\right)$ & 109.333(3) & $98.645(4)$ \\
\hline$\gamma /\left(^{\circ}\right)$ & 90 & 90 \\
\hline$V / \AA^{3}$ & $2412.40(10)$ & $6529.9(5)$ \\
\hline Z & 2 & 8 \\
\hline$F(000)$ & 1488 & 2608 \\
\hline Crystal size $/ \mathrm{mm}$ & $0.29 \times 0.26 \times 0.25$ & $0.21 \times 0.18 \times 0.16$ \\
\hline$\theta$ range for data collection & $3.332-25.050$ & $3.265-25.050$ \\
\hline Limiting indices & $-19 \leq h \leq 11,-9 \leq k \leq 10,-17 \leq l \leq 21$ & $-28 \leq h \leq 19,-11 \leq k \leq 23,-15 \leq l \leq 16$ \\
\hline Reflections collected/unique $\left(R_{\text {int }}\right)$ & $8845 / 5582(0.0385)$ & $12181 / 5789(0.0660)$ \\
\hline$D_{\mathrm{c}} /\left(\mathrm{Mg} \cdot \mathrm{cm}^{-3}\right)$ & 2.184 & 1.306 \\
\hline$\mu / \mathrm{mm}^{-1}$ & 10.520 & 1.518 \\
\hline Data/restraints/parameters & $5582 / 61 / 677$ & $5789 / 0 / 343$ \\
\hline Goodness-of-fit on $F^{2}$ & 1.020 & 0.975 \\
\hline Final $R$ indices $[(I \geq 2 \sigma(I))] R_{1}, \mathrm{w} R_{2}$ & $0.0374,0.0450$ & $0.0707,0.1809$ \\
\hline$R$ indices (all data) $R_{1}, \mathrm{w} R_{2}$ & $0.0688,0.0742$ & $0.1320,0.2111$ \\
\hline Largest diff. peak and hole $/\left(\mathrm{e} \cdot \AA^{-3}\right)$ & 1.345 and -0.931 & 0.932 and -0.490 \\
\hline
\end{tabular}

\section{Results and Discussion}

\subsection{Hydrothermal Self-Assembly Synthesis}

Hydrothermal treatment of the aqueous mixtures composed of a metal(II) chloride $\left(\mathrm{PbCl}_{2}\right.$ or $\mathrm{ZnCl}_{2}$ ), 2-(5-carboxypyridin-2-yl)terephthalic acid as a principal building block, sodium hydroxide as a deprotonating agent, and an aromatic $N, N$-donor as a crystallization mediator (1,10-phenanthroline or 4,4'-bipyridine) resulted in the generation of two novel coordination compounds formulated as $\left\{\left[\mathrm{Pb}_{3}\left(\mu_{5} \text {-cpta)}\left(\mu_{6} \text {-cpta) }(\text { phen })_{2}\right] \cdot 2 \mathrm{H}_{2} \mathrm{O}\right\}_{\mathrm{n}}(\mathbf{1})\right.\right.$ and $\left\{\left[\mathrm{Zn}_{2}\left(\mu_{4} \text {-cpta }\right)(\mu-\mathrm{OH})\left(\mu-4,4^{\prime}-\text { bipy }\right)\right] \cdot 6 \mathrm{H}_{2} \mathrm{O}\right\}_{\mathrm{n}}(2)$. These were isolated as microcrystalline solids and analyzed by standard methods including single-crystal X-ray diffraction, which allowed the establishment of their intricate 3D metal-organic architectures. 


\subsection{Crystal Structure of $\left\{\left[\mathrm{Pb}_{3}\left(\mu_{5}-\mathrm{cpta}\right)\left(\mu_{6}-\mathrm{cpta}\right)(\text { phen })_{2}\right] \cdot 2 \mathrm{H}_{2} \mathrm{O}\right\}_{n}(\mathbf{1})$}

Compound 1 features a very complex 3D coordination polymer structure (Figure 1). An asymmetric unit of 1 contains three distinct $\mathrm{Pb}(\mathrm{II})$ atoms, two different $\mu_{5}-$ and $\mu_{6}-\mathrm{cpta}^{3-}$ blocks, three terminal phen ligands, and two lattice $\mathrm{H}_{2} \mathrm{O}$ molecules. Three $\mathrm{Pb}$ (II) centers adopt distinct coordination environments (Figure $1 \mathrm{a}$ and Figure $\mathrm{S} 1$ ). The $\mathrm{Pb} 1$ atom is seven-coordinate and has a distorted $\left\{\mathrm{PbN}_{2} \mathrm{O}_{5}\right\}$ geometry, which is completed by a pair of phen $\mathrm{N}$ atoms and five carboxylate $\mathrm{O}$ donors from four distinct $\mathrm{cpta}^{3-}$ moieties. The $\mathrm{Pb} 2$ center is also seven-coordinate and possesses a distorted $\left\{\mathrm{PbO}_{7}\right\}$ geometry, which is taken by seven $\mathrm{O}$ donor atoms from five different $\mathrm{cpta}^{3-}$ blocks. The six-coordinate $\mathrm{Pb} 3$ atom adopts a distorted $\left\{\mathrm{PbN}_{2} \mathrm{O}_{4}\right\}$ geometry, filled by a pair of phen $\mathrm{N}$ atoms and four $\mathrm{O}$ donors coming from two cpta ${ }^{3-}$ ligands. The $\mathrm{Pb}-\mathrm{O}[2.328(11)-2.913(10) \AA]$ and $\mathrm{Pb}-\mathrm{N}$ [2.577(15)-2.704(17) $\AA$ ] distances are comparable to those in related $\mathrm{Pb}$ (II) derivatives [21,22,40]. In $\mathbf{1}$, the cpta $^{3-}$ blocks behave as two different $\mu_{6}$ - and $\mu_{5}$-spacers (modes I and II, Scheme 1 ), in which the $\mathrm{COO}^{-}$groups exhibit the monodentate, bidentate, or bridging tridentate modes. Although the $\mathrm{N}$ atom of $_{\mathrm{cpta}^{3-}}{ }^{3-}$ remains uncoordinated, there is a rather short $\mathrm{Pb3} \ldots \mathrm{N} 1$ interaction (3.193 $\AA$ ). In the cpta ${ }^{3-}$ moieties, the dihedral angles between the two aromatic rings are 20.66 and $50.14^{\circ}$. Carboxylate groups of the $\mu_{6}$ - and $\mu_{5}-\mathrm{cpta}^{3-}$ blocks interlink the $\mathrm{Pb} 1$ and $\mathrm{Pb} 2$ nodes into 2D layer motifs, which are further interconnected via the $\mathrm{Pb} 3$ centers (through additional $\mathrm{Pb} 3-\mathrm{O}_{\text {carboxylate }}$ bonds) to give rise to a very complex 3D metal-organic architecture (Figure 1b).

To better understand this architecture, we generated its simplified underlying net (Figure 1c,d) that is constructed from the 5-, 4-, and 2-connected $\mathrm{Pb}$ centers $(\mathrm{Pb} 2, \mathrm{~Pb} 1$, and $\mathrm{Pb} 3$, respectively) as well as the 5- and 6-connected cpta ${ }^{3-}$ blocks. Topological analysis of this tetranodal 4,5,5,6-connected framework reveals a unique topology that is defined by the point symbol of $\left(4^{5} \cdot 6.8^{4}\right)\left(4^{5} \cdot 6\right)\left(4^{6} .6^{4} .8^{5}\right)\left(4^{6} \cdot 6^{4}\right)$, wherein the $\left(4^{5} .6 .8^{4}\right),\left(4^{5} .6\right),\left(4^{6} .6^{4} .8^{5}\right)$, and $\left(4^{6} .6^{4}\right)$ notations correspond to the $\mu_{5}$-cpta ${ }^{3-}, \mathrm{Pb} 1, \mu_{6}$-cpta ${ }^{3-}$, and $\mathrm{Pb} 2$ nodes, respectively. An unprecedented nature of the present topological net was confirmed by a search of different databases [38,39].
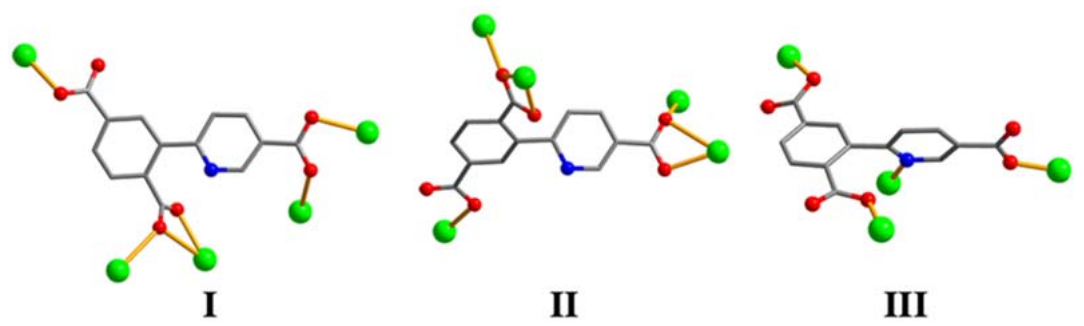

Scheme 1. Various coordination modes of $\mathrm{cpta}^{3-}$ blocks in $\mathbf{1}$ (modes I, II) and $\mathbf{2}$ (mode III).

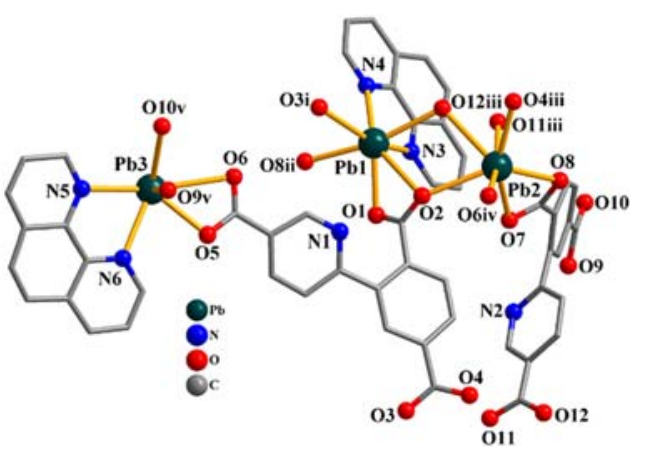

(a)

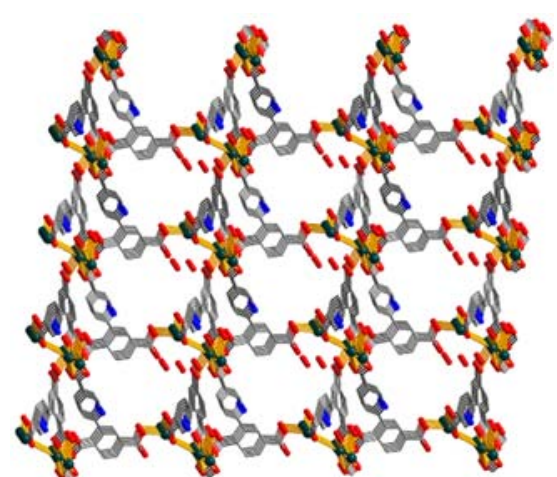

(b)

Figure 1. Cont. 


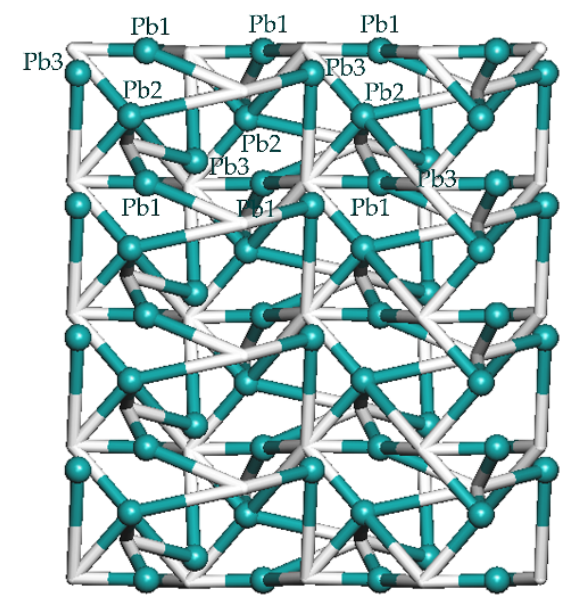

(c)

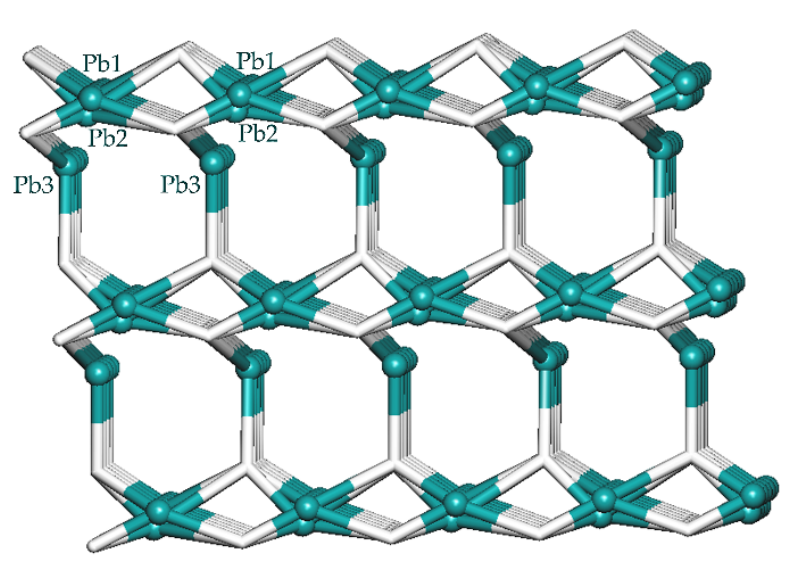

(d)

Figure 1. Structural fragments of 1. (a) Coordination environment around the $\mathrm{Pb}(\mathrm{II})$ atoms; $\mathrm{H}$ atoms are omitted for clarity. Symmetry code: $\mathrm{i}=x+1 / 2,-y, z+1 / 2 ; \mathrm{ii}=x, y+1, z$; iii $=x+1 / 2,-y-$ $1, z+1 / 2 ; \mathrm{iv}=x, y-1, z ; \mathrm{v}=x-1 / 2,-y, z+1 / 2$. (b) $3 \mathrm{D}$ coordination polymer seen along the $b$ axis. (c,d) Topological representation of an underlying tetranodal 4,5,5,6-connected net with the unique topology; views along the $c$ (c) and $b(\mathbf{d})$ axis. Color codes: 2-, 4-, and 5-connected Pb centers (turquoise balls; $\mathrm{Pb} 3, \mathrm{~Pb} 1$, and $\mathrm{Pb} 2$, respectively; partial labelling scheme is shown), centroids of 5- and 6-connected cpta ${ }^{3-}$ blocks (gray).

\subsection{Crystal Structure of $\left\{\left[\mathrm{Zn}_{2}\left(\mu_{4}-\mathrm{cpta}\right)(\mu-\mathrm{OH})\left(\mu-4,4^{\prime}-\text {-bipy }\right)\right] \cdot 6 \mathrm{H}_{2} \mathrm{O}\right\}_{n}(\mathbf{2})$}

Compound 2 also features a 3D metal-organic framework which, in contrast to $\mathbf{1}$, is driven by $\mu_{4}$-cpta $^{3-}$ spacers along with additional $\mu-\mathrm{OH}^{-}$and $\mu-4,4^{\prime}$-bipy linkers. The asymmetric unit of 2 bears two crystallographically unique $\mathrm{Zn}(\mathrm{II})$ atoms, a $\mu_{4}$-cpta ${ }^{3-}$ block, a $\mu-\mathrm{OH}^{-}$group, a $\mu-4,4^{\prime}$-bipy ligand, and six water molecules of crystallization (Figure 2a and Figure S2). Both $\mathrm{Zn}$ atoms are four-coordinate and display distorted tetrahedral $\left\{\mathrm{ZnNO}_{3}\right\}$ or $\left\{\mathrm{ZnN}_{2} \mathrm{O}_{2}\right\}$ geometries. $\mathrm{Zn} 1$ center is bound by two $\mathrm{O}$ atoms from two $\mu_{4}$-cpta ${ }^{3-}$ blocks, a $\mu-\mathrm{OH}^{-}$linker, and an $\mathrm{N}$ donor from the $\mu-4,4^{\prime}$-bipy moiety. $\mathrm{Zn} 2$ atom is coordinated by one $\mathrm{O}$ and one $\mathrm{N}$ atom from two different $\mu_{4}$-cpta ${ }^{3-}$ blocks, one $\mu-\mathrm{OH}^{-}$ group, and one $\mathrm{N}$ atom from the $\mu-4,4^{\prime}$-bipy ligand. The $\mathrm{Zn}-\mathrm{O}[1.936(5)-1.977(5) \AA]$ and $\mathrm{Zn}-\mathrm{N}$ [2.030(6)-2.050(6) $\AA]$ bond lengths are within typical values for related $\mathrm{Zn}$ (II) derivatives [16,24,25]. In 2, the cpta ${ }^{3-}$ block acts a $\mu_{4}-\mathrm{N}, \mathrm{O}_{3}$-spacer (mode III, Scheme 1 ) and its $\mathrm{COO}^{-}$groups adopt a monodentate mode; a dihedral angle between the aromatic rings in cpta ${ }^{3-}$ is $70.81^{\circ}$. One $\mu-\mathrm{OH}^{-}$linker bridge the two adjacent $\mathrm{Zn}$ (II) centers ( $\mathrm{Zn} 1$ and $\mathrm{Zn} 2$ ) to furnish a dinuclear $\mathrm{Zn}_{2}$ unit (Figure 2a) with a $\mathrm{Zn} \cdots \mathrm{Zn}$ separation of 3.488(5) $\AA$ and the $\mathrm{Zn}-\mathrm{O}-\mathrm{Zn}$ angle of $128.41(5)^{\circ}$. These $\mathrm{Zn}_{2}$ units are multiply interlinked by the remaining $\mathrm{COO}^{-}$groups of the $\mu_{4}-\mathrm{cpta}^{3-}$ blocks and $\mu-4,4^{\prime}$-bipy ligands to generate a 3D metal-organic framework (Figure $2 b$ ). The PLATON analysis revealed that the framework is porous with a free volume of $25.4 \%$ of the crystal volume [37]. The elimination of guest water molecules increases the effective free volume up to $30.7 \%$ of the crystal volume.

From the topological perspective, the present 3D framework (Figure $2 \mathrm{c}$ ) is built from the 4-connected $\mathrm{Zn} 1$ and $\mathrm{Zn} 2$ centers (topologically equivalent), the 4 -connected $\mu_{4}$-cpta ${ }^{3-}$ blocks and the 2-connected $\mu-\mathrm{OH}^{-}$and $\mu-4,4^{\prime}$-bipy linkers. Hence, this binodal 4,4-connected framework can be classified within the isx topological type and described by the point symbol of $\left(4.5^{2} \cdot 6^{3}\right)_{2}\left(4^{2} \cdot 5 \cdot 6^{3}\right)$. Although the present topological type has been theoretically predicted and referenced in databases [38], compound $\mathbf{2}$ appears to represent the first synthesized and structurally characterized metal-organic framework with the isx topology. 

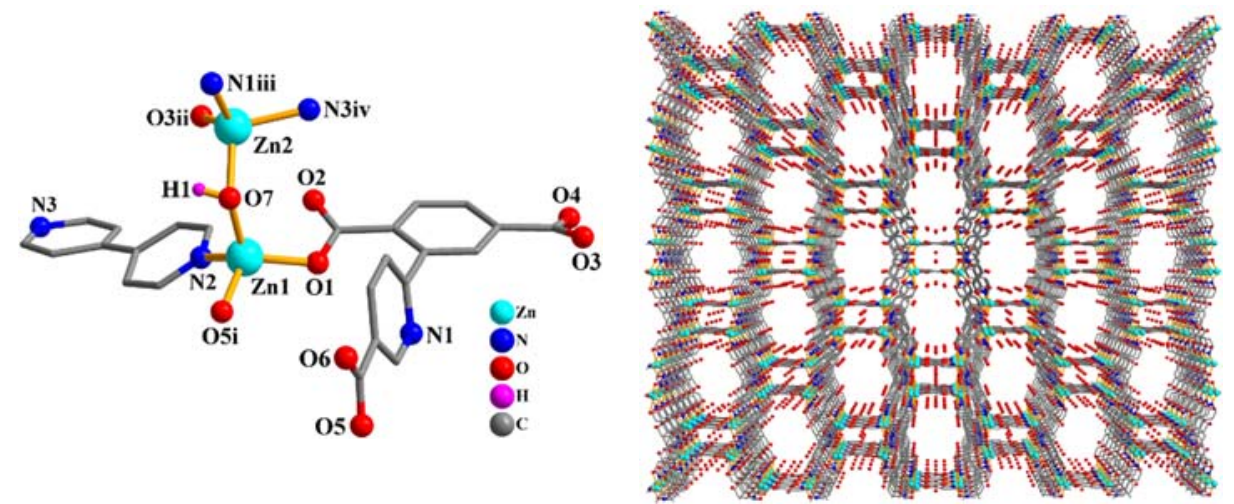

(a)

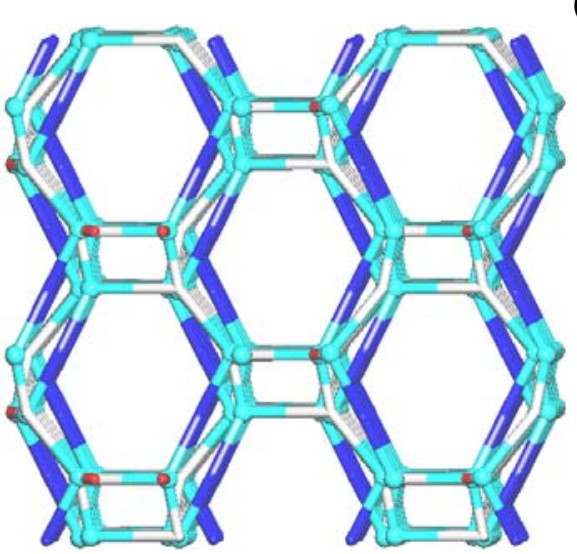

(b)

(c)

Figure 2. Structural fragments of 2. (a) Coordination environment around the $\mathrm{Zn}(\mathrm{II})$ atoms; $\mathrm{H}$ atoms are omitted for clarity except one of $\mathrm{OH}^{-}$group. Symmetry code: $\mathrm{i}=-x,-y,-z ; \mathrm{ii}=-x+1 / 2, y+1 / 2$, $-z+1 / 2$; iii $=x,-y, z+1 / 2$; iv $=-x+1 / 2, y-1 / 2,-z+1 / 2$. (b) 3D metal-organic framework seen along the $c$ axis. (c) Topological representation of an underlying binodal 4,4-connected framework with the isx topology; view along the $c$ axis. Color codes: 4-connected Zn centers (cyan balls), centroids of 4 -connected cpta ${ }^{3-}$ blocks (gray), centroids of 2-connected $\mu-\mathrm{OH}^{-}$(red) and $\mu-4,4^{\prime}$-bipy (blue) linkers.

\subsection{Thermogravimetric and Powder X-ray Diffraction Analysis}

Thermal behavior and stability of CP $\mathbf{1}$ and MOF 2 were studied by thermogravimetric analysis (TGA) in the $25-800{ }^{\circ} \mathrm{C}$ temperature range under $\mathrm{N}_{2}$ atmosphere (Figure S1). TGA curve of 1 shows a release of two lattice water molecules between 42 and $86^{\circ} \mathrm{C}$ (exptl, 2.6\%; calcd, $2.3 \%$ ); a dehydrated solid remains stable on further heating up to $304{ }^{\circ} \mathrm{C}$. In 2, a weight loss in the $32-94{ }^{\circ} \mathrm{C}$ range corresponds to a removal of six lattice water molecules (exptl, 15.3\%; calcd, 15.1\%) and the dehydrated material keeps its integrity on heating up to $308^{\circ} \mathrm{C}$.

Microcrystalline samples of $\mathbf{1}$ and $\mathbf{2}$ were also investigated by PXRD (powder X-ray diffraction) analysis. PXRD patterns of the bulk products are given in Figures S4 and S5. The experimental results match those simulated from the single-crystal X-ray diffraction data, thus confirming a phase purity of the bulk samples of $\mathbf{1}$ and $\mathbf{2}$.

\subsection{Luminescent Properties}

Solid-state emission spectra of compounds $\mathbf{1}, \mathbf{2}$, and $\mathrm{H}_{3}$ cpta were recorded at room temperature using the microcrystalline samples (Figure 3). The emission spectrum of $\mathrm{H}_{3}$ cpta displays a band with a maximum at $371 \mathrm{~nm}\left(\lambda_{\mathrm{ex}}=320 \mathrm{~nm}\right)$. In contrast, CP 1 and MOF 2 show more intense emission peaks with maxima at $374\left(\lambda_{\mathrm{ex}}=318 \mathrm{~nm}\right)$ and $376 \mathrm{~nm}\left(\lambda_{\mathrm{ex}}=348 \mathrm{~nm}\right)$, respectively. This observation 
suggests that the emission bands in $\mathbf{1}$ and $\mathbf{2}$ are similar to those of the free $\mathrm{H}_{3}$ cpta ligand, allowing their assignment to the intraligand $\pi-\pi^{*}$ or $n-\pi^{*}$ transitions $[16,24,40]$.

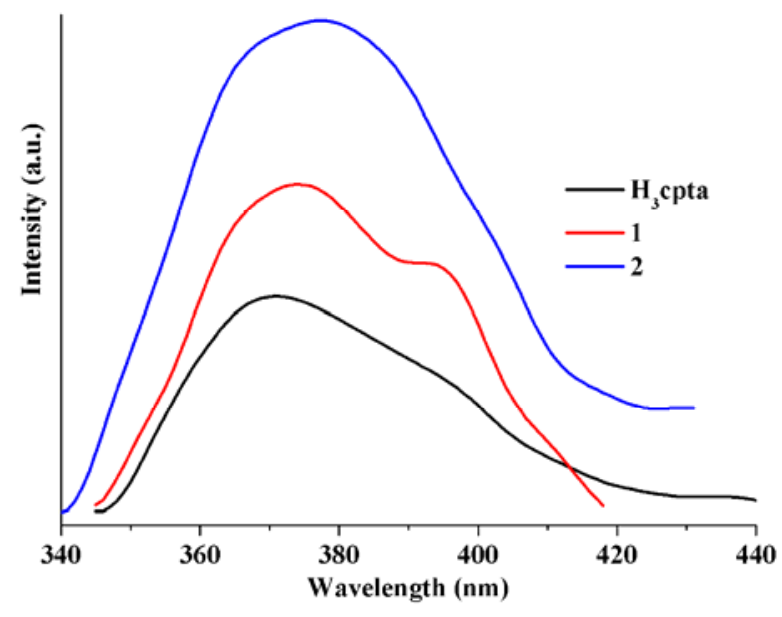

Figure 3. Solid-state emission spectra of $\mathrm{H}_{3}$ cpta, $\mathrm{CP} 1$ and MOF 2 at room temperature; $\lambda_{\mathrm{ex}}$ is 320 ( $\mathrm{H}_{3}$ cpta), 318 (1), or $\left.348 \mathrm{~nm}(\mathbf{2})\right)$.

\section{Conclusions}

In the present study, we applied a versatile aqueous medium approach for the hydrothermal synthesis of two novel 3D metal-organic architectures derived from 2-(5-carboxypyridin-2-yl)terephthalic acid ( $\left.\mathrm{H}_{3} \mathrm{cpta}\right)$ as an underexplored tricarboxylate building block with a phenyl-pyridine core. In fact, the obtained coordination polymer $\mathbf{1}$ and metal-organic framework 2 represent the first structurally characterized $\mathrm{Pb}$ (II) and $\mathrm{Zn}$ (II) coordination compounds assembled from $\mathrm{H}_{3}$ cpta.

Additionally, structural and topological features of $\mathbf{1}$ and $\mathbf{2}$ were highlighted, namely by performing the analysis and classification of their intricate underlying 3D networks. As a result, a topologically unique 4,5,5,6-connected net was identified in the structure of $\mathbf{1}$, whereas a very rare 4,4-connected net with the isx topology was determined in the structure of 2 . Hence, the current work also contributes to the identification of topologically rare and unprecedented nets in metal-organic architectures. Both compounds also show promising luminescent properties.

Further research on widening a still very limited family of CPs and MOFs driven by $\mathrm{H}_{3}$ cpta and related pyridine-tricarboxylate building blocks, as well as on establishing their functional properties and applications is currently under way in our laboratories.

Supplementary Materials: The following are available online at http:/ /www.mdpi.com/2073-4352/8/9/353/s1, Figures S1 and S2: ORTEP ellipsoid plots, Figure S3: TGA curves, Figures S4 and S5: PXRD patterns, Figure S6: excitation spectra, Tables S1 and S2: selected bonding and H-bonding parameters for compounds 1 and 2.

Author Contributions: Conceptualization, J.G. and A.M.K.; Data curation, Y.C. and M.W.; Funding acquisition, A.M.K. and Z.G.; Investigation, Y.C., M.W. and J.G.; Methodology, Z.G.; Supervision, J.G.; Writing-original draft, J.G. and A.M.K.; Writing-review \& editing, A.M.K.

Funding: This research was funded by the Foundation of Clinical Science and Technology of Wuxi (No. MS 201609), the Foundation for Science and Technology (FCT) and Portugal 2020 (LISBOA-01-0145-FEDER-029697, UID/QUI/00100/2013), and the RUDN University (the publication was prepared with the support of the RUDN University Program 5-100).

Conflicts of Interest: The authors declare no conflict of interest.

\section{References}

1. Zhu, Q.L.; Xu, Q. Metal-organic framework composites. Chem. Soc. Rev. 2014, 43, 5468-5512. [CrossRef] [PubMed] 
2. Adil, K.; Belmabkhout, Y.; Pillai, R.S.; Cadiau, A.; Bhatt, P.M.; Assen, A.H.; Maurin, G.; Eddaoudi, M. Gas/vapour separation using ultra-microporous metal-organic frameworks: Insights into the structure/separation relationship. Chem. Soc. Rev. 2017, 46, 3402-3430. [CrossRef] [PubMed]

3. Papazoi, E.; Douvali, A.; Rapti, S.; Skliri, E.; Armatas, G.S.; Papaefstathiou, G.S.; Wang, X.; Huang, Z.F.; Kaziannis, S.; Kosmidis, C. A microporous $\mathrm{Mg}^{2+}$ MOF with cation exchange properties in a single-crystal-to-single-crystal fashion. Inorg. Chem. Front. 2017, 4, 530-536. [CrossRef]

4. Cui, Y.J.; Yue, Y.F.; Qian, G.D.; Chen, B.L. Luminescent functional metal-organic frameworks. Chem. Rev. 2012, 112, 1126-1162. [CrossRef] [PubMed]

5. Lustig, W.P.; Mukherjee, S.; Rudd, N.D.; Desai, A.V.; Li, J.; Ghosh, S.K. Metal-organic frameworks: Functional luminescent and photonic materials for sensing applications. Chem. Soc. Rev. 2017, 46, 3242-3285. [CrossRef] [PubMed]

6. Férey, G. Hybrid porous solids: Past, present, future. Chem. Soc. Rev. 2008, 37, 191-214. [CrossRef] [PubMed]

7. Zeng, M.H.; Yin, Z.; Tan, Y.X.; Zhang, W.X.; He, Y.P.; Kurmoo, M. Nanoporous cobalt(II) MOF exhibiting four magnetic ground states and changes in gas sorption upon post-synthetic modification. J. Am. Chem. Soc. 2014, 136, 4680-4688. [CrossRef] [PubMed]

8. Meng, X.X.; Zhang, X.J.; Bing, Y.M.; Xu, N.; Shi, W.; Cheng, P. In situ generation of NiO nanoparticles in a magnetic metal-organic framework exhibiting three-dimensional magnetic ordering. Inorg. Chem. 2016, 55, 12938-12943. [CrossRef] [PubMed]

9. Zhou, Y.L.; Wu, M.C.; Zeng, M.H.; Liang, H. Magneto-structural correlation in a metamagnetic cobalt(II)-based pillared trilayer motif constructed by mixed pyridyl-type carboxylate ligands. Inorg. Chem. 2009, 48, 10146-10150. [CrossRef] [PubMed]

10. Fidelli, A.M.; Armakola, E.; Demadis, K.D.; Kessler, V.G.; Escue, A.; Papaefstathiou, G.S. Cu-II frameworks from di-2-pyridyl ketone and benzene-1,3,5-triphosphonic acid. Eur. J. Inorg. Chem. 2018, 91-98. [CrossRef]

11. Murray, L.J.; Dincă, M.; Long, L.R. Hydrogen storage in metal-organic frameworks. Chem. Soc. Rev. 2009, 38, 1294-1314. [CrossRef] [PubMed]

12. Li, J.R.; Kuppler, R.J.; Zhou, H.C. Selective gas adsorption and separation in metal-organic frameworks. Chem. Soc. Rev. 2009, 38, 1477-1504. [CrossRef] [PubMed]

13. Kourtellaris, A.; Moushi, E.E.; Spanopoulos, I.; Tampaxis, C.; Steriotis, T.A.; Papaefstathiou, G.S.; Trikalitis, P.N.; Tasiopoulos, A.J. A microporous $\mathrm{Cu}^{2+} \mathrm{MOF}$ based on a pyridyl isophthalic acid Schiff base ligand with high $\mathrm{CO}_{2}$ uptake. Inorg. Chem. Front. 2016, 3, 1527-1535. [CrossRef]

14. Zhang, X.L.; Zhan, Z.Y.; Liang, X.Y.; Chen, C.; Liu, X.L.; Jia, Y.J.; Hu, M. Lanthanide-MOFs constructed from mixed dicarboxylate ligands as selective multi-responsive luminescent sensors. Dalton Trans. 2018, 47, 3272-3282. [CrossRef] [PubMed]

15. Chen, C.H.; Wang, X.S.; Li, L.; Huang, Y.B.; Cao, R. Highly selective sensing of $\mathrm{Fe}^{3+}$ by an anionic metal-organic framework containing uncoordinated nitrogen and carboxylate oxygen sites. Dalton Trans. 2018, 47, 3452-3458. [CrossRef] [PubMed]

16. Gu, J.Z.; Liang, X.X.; Cui, Y.H.; Wu, J.; Shi, Z.F.; Kirillov, A.M. Introducing 2-(2-carboxyphenoxy)terephthalic acid as a new versatile building block for design of diverse coordination polymers: Synthesis, structural features, luminescence sensing, and magnetism. CrystEngComm 2017, 19, 2570-2588. [CrossRef]

17. Gu, J.Z.; Cai, Y.; Liang, X.X.; Wu, J.; Shi, Z.F.; Kirillov, A.M. Bringing 5-(3,4-dicarboxylphenyl) picolinic acid to crystal engineering research: Hydrothermal assembly, structural features, and photocatalytic activity of $\mathrm{Mn}, \mathrm{Ni}, \mathrm{Cu}$, and Zn coordination polymers. CrystEngComm 2018, 20, 906-916. [CrossRef]

18. Fernandes, T.A.; Santos, C.I.M.; André, V.; Kłak, J.; Kirillova, M.V.; Kirillov, M.V. Copper(II) coordination polymers self-assembled from aminoalcohols and pyromellitic acid: Highly active precatalysts for the mild water-promoted oxidation of alkanes. Inorg. Chem. 2016, 55, 125-135. [CrossRef] [PubMed]

19. Sotnik, S.A.; Polunin, R.A.; Kiskin, M.A.; Kirillov, A.M.; Dorofeeva, V.N.; Gavrilenko, K.S.; Eremenko, I.L.; Novotortsev, V.M.; Kolotilov, S.V. Heterometallic coordination polymers assembled from trigonal trinuclear $\mathrm{Fe}_{2} \mathrm{Ni}$-pivalate blocks and polypyridine spacers: Topological diversity, sorption, and catalytic properties. Inorg. Chem. 2015, 54, 5169-5181. [CrossRef] [PubMed]

20. Gupta, S.; Kirillova, M.V.; Guedes da Silva, M.F.C.; Pombeiro, A.J.L.; Kirillov, A.M. Alkali metal directed assembly of heterometallic V.-v/M. (M. = Na, K., Cs) coordination polymers: Structures, topological analysis, and oxidation catalytic properties. Inorg. Chem. 2013, 52, 8601-8611. [CrossRef] [PubMed] 
21. Gu, J.Z.; Kirillov, A.M.; Wu, J.; Lv, D.Y.; Tang, Y.; Wu, J.C. Synthesis, structural versatility, luminescent and magnetic properties of a series of coordination polymers constructed from biphenyl-2,4,4'-tricarboxylate and different N-donor ligands. CrystEngComm 2013, 15, 10287-10303. [CrossRef]

22. Shao, Y.L.; Cui, Y.H.; Gu, J.Z.; Wu, J.; Wang, Y.W.; Kirillov, A.M. Exploring biphenyl-2,4,4'-tricarboxylic acid as a flexible building block for the hydrothermal self-assembly of diverse metal-organic and supramolecular networks. CrystEngComm 2016, 18, 765-778. [CrossRef]

23. Jia, J.H.; Athwal, H.S.; Blake, A.J.; Champness, N.R.; Hubberstey, P.; Schroder, M. Increasing nuclearity of secondary building units in porous cobalt(II) metal-organic frameworks: Variation in structure and $\mathrm{H}_{2}$ adsorption. Dalton Trans. 2011, 40, 12342-12349. [CrossRef] [PubMed]

24. Gu, J.Z.; Liang, X.X.; Cui, Y.H.; Wu, J.; Kirillov, A.M. Exploring 4-(3-carboxyphenyl)picolinic acid as a semirigid building block for the hydrothermal self-assembly of diverse metal-organic and supramolecular networks. CrystEngComm 2017, 19, 117-128. [CrossRef]

25. Gu, J.Z.; Cui, Y.H.; Liang, X.X.; Wu, J.; Lv, D.Y.; Kirillov, A.M. Structurally distinct metal-organicand H-bonded networks derived from 5-(6-carboxypyridin-3-yl)isophthalic acid: Coordination and template effect of 4,4'-bipyridine. Cryst. Growth Des. 2016, 16, 4658-4670. [CrossRef]

26. Gu, J.Z.; Gao, Z.Q.; Tang, Y. $\mathrm{pH}$ and auxiliary ligand influence on the structural variations of 5(2'-carboxylphenyl) nicotate coordination polymers. Cryst. Gorwth Des. 2012, 12, 3312-3323. [CrossRef]

27. Gu, J.Z.; Wen, M.; Liang, X.X.; Shi, Z.; Kirillova, M.V.; Kirillov, A.M. Multifunctional aromatic carboxylic acids as versatile building blocks for hydrothermal design of coordination polymers. Crystals 2018, 8, 83. [CrossRef]

28. Yan, W.; Han, L.J.; Jia, H.L.; Shen, K.; Wang, T.; Zheng, H.G. Three highly stable cobalt MOFs based on "Y"-shaped carboxylic acid: Synthesis and absorption of anionic dyes. Inorg. Chem. 2016, 55, 8816-8821. [CrossRef] [PubMed]

29. Ning, Y.; Wang, L.; Yang, G.P.; Wu, Y.L.; Bai, N.N.; Zhang, W.Y.; Wang, Y.Y. Four new lanthanide-organic frameworks: Selective luminescent sensing and magnetic properties. Dalton Trans. 2016, 45, 12800-12806. [CrossRef] [PubMed]

30. Lin, Z.J.; Han, L.W.; Wu, D.S.; Huang, Y.B.; Cao, R. Structure versatility of coordination polymers constructed from a semirigid tetracarboxylate ligand: Syntheses, structures, and photoluminescent properties. Cryst. Growth Des. 2013, 13, 255-263. [CrossRef]

31. Xu, W.; Si, Z.X.; Xie, M.; Zhou, L.X.; Zheng, Y.Q. Experimental and theoretical approaches to three uranyl coordination polymers constructed by phthalic acid and $N, N^{\prime}$-donor bridging ligands: Crystal structures, luminescence, and photocatalytic degradation of tetracycline hydrochloride. Cryst. Growth Des. 2017, 17, 2147-2157. [CrossRef]

32. Wu, Y.P.; Wu, X.Q.; Wang, J.F.; Zhao, J.; Dong, W.W.; Li, D.S.; Zhang, Q.C. Assembly of two novel $\mathrm{Cd}_{3} /\left(\mathrm{Cd}_{3}\right.$ $+\mathrm{Cd}_{5}$ )-cluster-based metal-organic frameworks: Structures, luminescence, and photocatalytic degradation of organic dyes. Cryst. Growth Des. 2016, 16, 2309-2316. [CrossRef]

33. Shao, Y.L.; Cui, Y.H.; Gu, J.Z.; Kirillov, A.M.; Wu, J.; Wang, Y.W. A variety of metal-organic and supramolecular networks constructed from a new flexible multifunctional building block bearing picolinate and terephthalate functionalities: Hydrothermal self-assembly, structural features, magnetic and luminescent properties. RSC Adv. 2015, 5, 87484-87495. [CrossRef]

34. Li, Y.; Zhou, Q.; Qiu, W.D.; You, A.; Zou, X.Z.; Gu, J.Z.; Chen, B. Mn(II) and Co(II) coordination polymers constructed from pyridine-tricarboxylate ligand. Chin. J. Struct. Chem. 2017, 36, 661-670.

35. Sheldrick, G.M. SHELXS-97, Program for X-ray Crystal Structure Determination; University of Gottingen: Göttingen, Germany, 1997.

36. Sheldrick, G.M. SHELXL-97, Program for X-ray Crystal Structure Refinement; University of Gottingen: Göttingen, Germany, 1997.

37. Van de Sluis, P.; Spek, A.L. Bypass-an effective merhve method for the refinement of crystal-structures containing disordered solvent regions. Acta Crystallogr. Sect. A 1990, 46, 194-201. [CrossRef]

38. Blatov, V.A. Multipurpose crystallochemical analysis with the program package TOPOS. IUCr CompComm Newsl. 2006, 7, 4-38. 
39. Blatov, V.A.; Shevchenko, A.P.; Proserpio, D.M. Applied topological analysis of crystal structures with the program package topospro. Cryst. Growth Des. 2014, 14, 3576-3586. [CrossRef]

40. Gu, J.Z.; Liang, X.X.; Cai, Y.; Wu, J.; Shi, Z.F.; Kirillov, A.M. Hydrothermal assembly, structures, topologies, luminescence, and magnetism of a novel series of coordination polymers driven by a trifunctional nicotinic acid building block. Dalton Trans. 2017, 46, 10908-10925. [CrossRef] [PubMed] 